\title{
Clinical Characteristics of Iraqi Women Who Had Plantar Fasciitis
}

\section{Sarah Tareq Abdulazeez ${ }^{1}$, Hazim Abdul Rahman Alhiti2 ${ }^{*}$, Manaf Abdulrahman Guma ${ }^{3}$}

${ }^{1}$ Specialist in Rheumatology and Rehabilitation Unit, Internal Medicine Department, Ramadi Teaching Hospital, Baghdad University

${ }^{2}$ General Surgeon Specialist, Head of Emergency Faculty, Academic lecturer in Higher Health Institute of Nursing-Al Anbar Health Directorate, Iraq ${ }^{3}$ Department of Biophysics, College of Applied sciences- Hit, University Of Anbar, Iraq

Correspondence to: Hazim Abdul Rahman Alhiti, General Surgeon Specialist, Head of Emergency Faculty, Academic lecturer in Higher Health Institute of Nursing-Al Anbar Health Directorate, Iraq

Received date: December 13, 2021; Accepted date: December 24, 2021; Published Date: December 30, 2021

Citation: Abdulazeez ST, Alhiti HAR, Guma MA (2021) Clinical Characteristics of Iraqi Women Who Had Plantar Fasciitis. J Clin Biomed Invest 1(2): pp. 1-4. doi: 10.52916/jcbi214009

Copyright: (C2021 Abdulazeez ST, et al. This is an open-access article distributed under the terms of the Creative Commons Attribution License, which permits unrestricted use, distribution and reproduction in any medium, provided the original author and source are credited.

\section{ABSTRACT}

Plantar fasciitis is a common complaint. This paper aimed to find the clinical characteristics of Al-Ramadi Women who had Plantar fasciitis. A specialist rheumatologist in Al-Ramadi Teaching Hospital collected this prospective report from 170 Iraqi women, aged (25-70) years, who had plantar fasciitis between 1st January 2019 to 1st January 2020. Our findings showed that the most common affected age was between (40-49) years among all women who suffered from intense sharp painful heels at the start of walking. There were 66 women (38\%) between (40-49) years plus 32 women (18\%) their BMI was between (30-34\%). In the commonest age group, there were 37 women (21.7\%) who had Calcaneal spur and five women $(0.2 \%)$ who had Diabetes Mellitus. Therefore, it can be clearly said that Plantar Fasciitis is an evidence for obese due to the statistical analysis carried on the middle-aged Iraqi women who had intense sharp painful heels at the start of walking plus calcaneal spur in the lateral X-ray.

\section{Keywords:}

Characteristics, Al-Anbar, Iraq, Women, Plantar Fasciitis.

\section{Introduction}

Plantar fasciitis is a common connective tissue disease of the foot arch. Moreover, it causes a severe painful heel at the initial steps of the morning and sometimes after a rest. Subsequently, plantar fasciitis started at early movements of the foot up towards the shin [1].

Diagnosis of Plantar fasciitis is clinical-base on the pain characteristics and examination. Moreover, in the majority of cases, clinical diagnosis is enough. Subsequently, plantar fasciitis affects most humans during middle age. Accordingly, plantar fasciitis is common in military recruits, women, young athletes, and obese people [2].

Plantar fasciitis shows various risk factors like standing a long time, excessive exercise, the rough Achilles tendon, and the inward rolling of the foot. Thus, it causes a collagen breakdown plus tinny tears and scarring. Moreover, there are microscopic findings that include myxomatous degeneration with connective tissue calcium deposits [3].

Excessive movements during extravagant walking and longstanding standing can cause plantar fasciitis. Moreover, some experts imply the Windlass mechanism due to an extreme strain on the calcaneal tuberosity. Furthermore, the other scientists believed that it is a tendon injury of the flexor digitorum brevis muscle. The previous studies showed a correlation between tight footwear and Achilles tendon stretches as significant risk factors [4].

A single article presents in the "Iraqi scientific journals" concerning Laser treatment in Iraqi patients who suffers plantar fasciitis. Moreover, eight Iraqi articles on the same website focused on the various therapeutic choices for manipulating heel pain. Furthermore, there are thousands of papers on google scholar about plantar fasciitis. Subsequently, these studies cover all aspects of plantar fasciitis. Therefore, these numbers indicate the importance and consequence of plantar fasciitis on human life [5].

This original study is the first study in Anbar province and AlRamadi city concerning plantar fasciitis. So, this study aimed to find the characteristics of Ramadi Women who had plantar fasciitis.

This study tried to answer the below questions:

- What is the relation of groups of body mass index (\%) relative to age groups (years)?

- What is the relation of three selected variables relative to age groups (years)?

- $\quad$ Are these risks similar or different from other studies?

\section{Material and Methods}

A specialist rheumatologist at the Rheumatology clinic in Al-Ramadi Teaching Hospital carried this prospective crosssectional report from 1st January 2019 to 1st January 2020. This paper held a haphazard collection of data (minus their names) from 170 Iraqi women, aged (25-70) years old, who had plantar fasciitis. The history of the patients was considered, then the examinations followed by laboratory investigations and lateral foot radiographs. The ethical agreement approved the study. Microsoft Excel 2010 was used for data analysis. The women who refused the study were excluded. The patients were asked about the history of Diabetes Mellitus, then a random blood sugar RBS test was checked by venous sample through "SCILOGEX SP-UV 1000 Spectrophotometer". RBS test was considered as uncontrolled if it is higher than $200 \mathrm{mg} / \mathrm{dl}$.

The patients were questioned regarding Gout, then a uric acid was confirmed and checked via blood sample on " Mca-8000A Medical Hospital Lab Clinic Semi-Auto Chemistry Analyzer". Uric acid was supposed to be abnormal if it was higher than $6.0 \mathrm{mg} /$ 
dl (female).

\section{Results}

Of 170 sufferers, the most common age group affected was between (40-49) years. There were 66 women (38\%) were between (40-49) years plus 32 women (18\%) their BMI between (30-34\%). In this age group, there were 37 women (21.7\%) who had Calcaneal spur and five women $(0.2 \%)$ who had Diabetes Mellitus, with six women $(0.3 \%)$ had Gout.

Table 1: Relation of groups of body mass index (\%) relative to age groups (years) ( $N=170)$.

\begin{tabular}{|l|l|l|l|l|l|}
\hline & $20-25 \%$ & $26-29 \%$ & $30-34 \%$ & More than 35\% & Total \\
\hline $21-29$ years & $6(0.3 \%)$ & $2(0.1 \%)$ & $1(0.05 \%)$ & $0(0 \%)$ & $9(0.5 \%)$ \\
\hline $30-39$ years & $4(0.2 \%)$ & $7(0.4 \%)$ & $26(15 \%)$ & $8(0.4 \%)$ & $45(26 \%)$ \\
\hline $40-49$ years & $3(0.17 \%)$ & $11(6.4 \%)$ & $32(18 \%)$ & $20(11.7 \%)$ & $66(38 \%)$ \\
\hline $50-59$ years & $1(0.05 \%)$ & $5(0.2 \%)$ & $26(15 \%)$ & $8(0.4 \%)$ & $40(23.5 \%)$ \\
\hline $60-69$ years & $4(0.2 \%)$ & $0(0 \%)$ & $1(0.05 \%)$ & $5(0.2 \%)$ & $10(0.58 \%)$ \\
\hline Total & $18(10.5 \%)$ & $25(14 \%)$ & $86(50 \%)$ & $41(24 \%)$ & $170(100 \%)$ \\
\hline
\end{tabular}

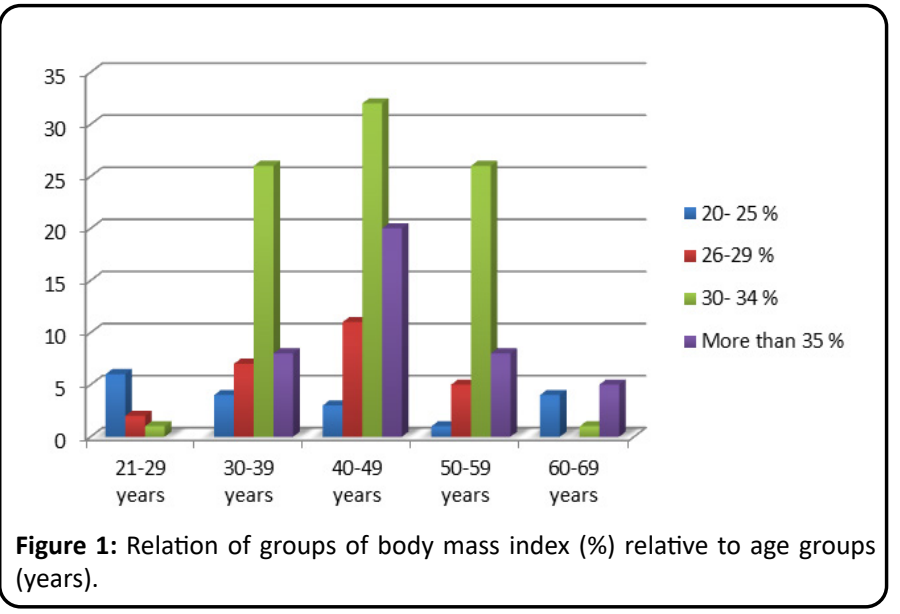

Table 2: Relation of three selected variables relative to age groups (years) $(\mathrm{N}=170)$.

\begin{tabular}{|l|l|l|l|}
\hline & $\begin{array}{l}\text { Calcaneal } \\
\text { spur }\end{array}$ & $\begin{array}{l}\text { Diabetes } \\
\text { mellitus }\end{array}$ & Gout \\
\hline $25-29$ years & $4(0.2 \%)$ & $0(0 \%)$ & $0(0 \%)$ \\
\hline $30-39$ years & $23(13.5 \%)$ & $3(0.17 \%)$ & $2(0.1 \%)$ \\
\hline $40-49$ years & $37(21.7 \%)$ & $5(0.2 \%)$ & $6(0.3 \%)$ \\
\hline $50-59$ years & $23(13.5 \%)$ & $1(0.05 \%)$ & $14(8.2 \%)$ \\
\hline $60-69$ years & $6(0.3 \%)$ & $1(0.05 \%)$ & $5(0.2 \%)$ \\
\hline Total & $93(54.7 \%)$ & $10(0.58 \%)$ & $27(15.8 \%)$ \\
\hline
\end{tabular}

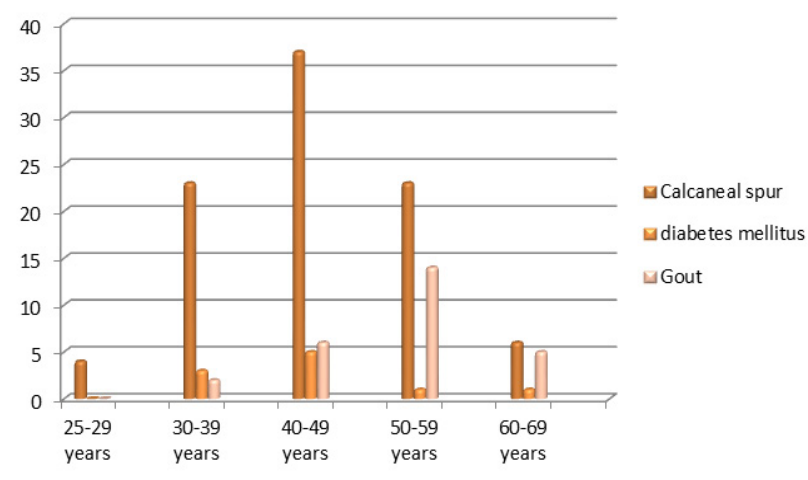

Figure 2: Relation of three selected variables relative to age groups (years) $(\mathrm{N}=170)$.

\section{Discussion}

This original study is the first study in the Anbar province and Al-Ramadi city in Iraq concerning plantar fasciitis. The study aimed to investigate the characteristics of Women in Ramadi who had plantar fasciitis. A specialist rheumatologist at the Rheumatology clinic in Ramadi Teaching Hospital carried this prospective cross-sectional report from 1st January 2019 to 1st January 2020.

Table 1 and figure 1 clearly show the relation of groups of body mass index (\%) regarding to age groups (years) $(\mathrm{N}=170)$. Of 170 sufferers, the most common age group affected was shown to be between (40-49) years.

This finding confirmed the worldwide known findings, which possibly due to particular kinds of stressful activities in this group like long-distance running or dance. Accordingly, in Ramadi, these stressful activities are probably due to longstanding in their kitchen or climbing stairs. Furthermore, these home activities increased in special times like before Muslim AID [6]. However, there were sixty-six women (38\%) who were between (40-49) years. This result indicates that other age groups also suffered, but to a less extent. Besides, this had best noticed in table 1 and figure 1, there were 45 women (26\%) between 30-39 years old. This outcome because of their excessive home duties and active lifestyle. On the other hand, there were forty women (23.5\%) who also suffered, but lesser than both of the above two groups. This is due to elder women sufferings, BMI, and lazy lifestyle due to their responsibilities in the homework [7]. There were thirty-two women (18\%) whose BMI between (30$34 \%$ ). This outcome went with various previous studies on this topic. Thus, this outcome due to overweight that burden on the feet, the small muscles, weak ligaments and tendons of women feet. Moreover, the overweight aggravated by the long-standing in the kitchen or stressful activities rose a severe discomfort. Furthermore, the hormonal changes of their periods in this age group (40-49) years could worsen their suffering [8].

Moreover, morbid obesity is the cause of plantar fasciitis in all age groups. Accordingly, this finding is present in table 1 and figure 1. Additionally, there were forty-one women (24\%) who had a BMI over $35 \%$. Furthermore, you can see twenty women $(11.7 \%)$ who had a BMI over $35 \%$ in the age group (40-49) years. Besides, there were a similar number of obese women; eight women $(0.4 \%)$ in the age groups ( $30-39$ years) and ( $50-59$ years) 
and only five women (0.2\%) in the older age group (60-69) years [9].

Table 2 and figure2 declare the relation of three selected variables relative to age groups (years) $(\mathrm{N}=170)$.

In the age group (40-49) years, thirty-seven women (21.7\%) had Calcaneal spur. Moreover, this study's result declares that calcaneal spur is an additional risk factor, although it is not a mandatory risk. Furthermore, this study's outcome went with many nations' studies. Besides, the presence of calcaneal spur in the lateral foot radiograph gave the clinician more support to the diagnosis of plantar fasciitis. Therefore, the absence of calcaneal spur could not exclude the diagnosis of plantar fasciitis [10]. The calcaneal spur is present in ninety-three women $(54.7 \%)$ from the total number of sufferers. Thus, the rheumatologist must seek the calcaneal spur for confirmation of the diagnosis of plantar fasciitis. Moreover, there was an equal number of women; twenty-three sufferers (13.5\%) in the age groups (30-39) and (50-59) years which indicate that these ages ranges are not targeted by Calcaneal spur. Furthermore, the presence of calcaneal spur is less evidence and not very clear in the age groups (20-29) and (60-69) years. Therefore, the age group is the obvious risk factor of plantar fasciitis [11].

There were five women in the age group (40-49) years $(0.2 \%)$ who had Diabetes Mellitus. Furthermore, their random blood sugar tests were high. This study results similar to many established articles. Besides, in uncontrolled Diabetes Mellitus, there are many microvascular neurovascular and macrovascular changes. Moreover, peripheral pain perception in uncontrolled Diabetes Mellitus is disturbed; this adds more burden in women with plantar fasciitis [12].

To a certain extent, there were three women in the age group (30-39) years (0.17\%) with Diabetes Mellitus and plantar fasciitis. Moreover, there were a similar number of women who suffered from plantar fasciitis in other age groups and surely, except in younger women age group (20-29) years. Subsequently, plantar fasciitis is not a presentation of women who had Diabetes Mellitus because of their peripheral neuropathy. [13].

However, six women between (40-49) years old $(0.3 \%)$ had Gout. This is due to rare occurrence of plantar fasciitis in Gout women. Subsequently, the rheumatologist diagnosed Gout in these women by clinical means confirmed by high serum uric acid because of Gout presentations in different features and other parts of the patient foot. Furthermore, this article outcome went well with the distributed articles [14]. There were fourteen women (8.2\%) who had gout, but this event in the age group (50-59) years. Furthermore, this study finding was shown in older women which can be explained as due to impaired renal function in this age group. Moreover, obesity is more evident in this age group (as in table 1 and figure 1 ), so the association between obesity and gout increased the incidence of plantar fasciitis in this group [15].

The report of obesity in the age group (60-69) is less than in the (50-59) years. Hence, obesity is Intrinsically more significant factor than Gout in the predisposition of plantar fasciitis. .

Therefore, in this study, obesity as a risk factor is more important than Gout in plantar fasciitis [16].

\section{Conclusions}

Plantar Fasciitis is an evidence of obese in middle-aged Iraqi women who had intense sharp painful heels at the start of walking plus calcaneal spur in the lateral foot radiograph which need to be farther investigated in Diabetes Mellitus or Gout.

\section{Conflict of Interest}

None

\section{References}

1. Trojian T, Tucker AK (2019). Plantar Fasciitis. Am Fam Physician 99(12): pp. 744-750.

2. Gutteck N, Schilde S, Delank KS (2019) Pain on the Plantar Surface of the Foot. Dtsch Arztebl Int 116(6): pp. 83-88.

3. Guoa J, Liu X, Ding X (2018) Biomechanical and mechanical behavior of the plantar fascia in macro and micro structures. Jour of Biom 76(7): pp. 160-166.

4. Shiotani H, Mizokuchi T, Yamashita R (2020) Acute effects of long-distance running on mechanical and morphological properties of the human plantar fascia. Scand J Med Sci Sports 30(8): pp. 1-9.

5. Palomo-López P, de-Bengoa-Vallejo RB (2018) Impact of plantar fasciitis on the quality of life of male and female patients according to the Foot Health Status Questionnaire. J Pain Res 2018(11): pp. 875-880.

6. Granado MJ, Lohman EB, Daher NS (2019) Effect of Gender, Toe Extension Position, and Plantar Fasciitis on Plantar Fascia Thickness. Foot and Ankl Inter 40(4): pp. 439-446.

7. Lee KJ, Yu KP, Yoon YS (2018) Acquired Change and Pain of Foot in Elderly People. Clin Pain 17(1): pp. 16-25.

8. Vita M, Sedlackova Z (2019) Influence of female hormones on fascia elasticity: An elastography study. Clini Anat 32(7): pp. 941-947.

9. Taş S, Salkın Y (2020) Investigation of Plantar Pressure Distribution in Overweight and Obese Individuals. Bezm. Scie 8(1): pp. 14-8.

10. Zhang L, Cheng HW, Xiong LI (2020) The Relationship between Calcaneal Spur Type and Plantar Fasciitis in Chinese Population. BioMed Rese Inter 2020: pp. 34-41.

11. Rodríguez-Sanz D, Tovaruela-Carrión N (2018) Foot disorders in the elderly: A mini-review. Disease-a-Month 64(3): pp. 64-91.

12. Kimura T, Thorhauer ED, Kindig MW (2020) Neuropathy, claw toes, intrinsic muscle volume, and plantar aponeurosis thickness in diabetic feet. BMC Musculoskelet Disord 21: pp. 485- 491.

13. Gariani K, Waibel FWA (2020) Plantar Fasciitis in Diabetic Foot Patients: Risk Factors, Pathophysiology, Diagnosis, and Management. Diabetes Metab Syndr Obes 13:1271-1279.

14. Stewart S, Dalbeth N (2017) Clinically-evident tophi are associated with reduced muscle force in the foot and ankle in people with gout: a cross-sectional study. J Foot Ankle Res 10(25): pp. 23-31.

15. Bendell K, Agalliu B (2021) Simon Otter. Foot and Ankle Characteristics in Gout: A Systematic Review. AJORR 4: pp. 2835. 
Citation: Abdulazeez ST, Alhiti HAR, Guma MA (2021) Clinical Characteristics of Iraqi Women Who Had Plantar Fasciitis. J Clin Biomed Invest 1(2): pp. 1-4. doi: 10.52916/jcbi214009

16. Boules M, Batayyah E, Froylich D (2018). Effect of Surgical Podiatr Med Assoc 108 (6): pp. 442-448. Weight Loss on Plantar Fasciitis and Health-Care Use. J Am 